
\title{
$\angle$ Research Square \\ Determinants of Female Genital Mutilation/Cutting in Khartoum State - Sudan, 2020: A Cross-Sectional Study
}

Mustafa Khidir Mustafa Elnimeiri

Al-Neelain University Faculty of Medicine

Reem Mahmoud Mohamed Abdelbasit ( $\sim$ Rymmahmoud@gmail.com )

Al-Neelain University Faculty of Medicine https://orcid.org/0000-0002-2431-2047

Mohanad Kamaleldin Mahmoud Ibrahim

Ibn Sina Medical College

Dimetry Adel Dimetry Mingaryous

Sudan International University Faculty of Medicine

Taqwa Mohieldeen Hamid Abdelrahim

Central Bureau of Statistics

Shahenaz Seifaldeen Mustafa Satti

Al-Neelain University Faculty of Medicine

Research article

Keywords: Female genital cutting/mutilation (FGC/M), Determinants, Social norms, Sudan.

Posted Date: August 14th, 2020

DOl: https://doi.org/10.21203/rs.3.rs-42443/v1

License: (c) (1) This work is licensed under a Creative Commons Attribution 4.0 International License.

Read Full License 


\section{Abstract}

Background: Female genital cutting/mutilation (FGC/M) is deeply rooted and widely practiced in Sudan. Although the trend is slowly decreasing, the magnitude is still very high as the procedure has no known benefit but has many consequences. The aim of this study was to identify the causes and the risk factors associated with FGC/M among reproductive-age women in the country.

Methods: A community based cross-sectional survey was conducted among 902 women in the reproductive age (15-49) years in Khartoum State-Sudan, sampled proportionate to size using multistage clustering and participants were drawn using systematic probability sampling technique. Data were collected using a standardized administered questionnaire. Statistical analysis was done using bivariate and multivariate logistic regression.

Results: Among 902 women who participated in the study, $89 \%$ of were married and $48 \%$ of them got married for the first time at age less than 20 years. The commonest age for such practice was 6-7 years as stated by about $48 \%$ of them. There is a significant association between educational level of participants and practicing FGC/M among their daughters ( $P$ value=.0001) with a tendency of the participants who attained a higher educational levels to less subject their daughters to any form of $\mathrm{FGC/M}$. There is a significant association between the type of FGC/M of participants and the type of $\mathrm{FGC} / \mathrm{M}$ of their daughters ( $\mathrm{P}$ value= $=001$ ) with a tendency of the participants' daughters to be subjected to clitorectomy rather than pharaonic. $39 \%$ of the participants stated that they themselves influenced the decision to subject their daughters to $\mathrm{FGC} / \mathrm{M}$ while $32 \%$ of them stated that the grandmothers influence such a decision. The study revealed $45 \%$ of the participants believed in customs and traditions as the main reason for the conduct of FGC/M.

Conclusion: The FGC/M was widely practiced by the participants' families indicating the deeply rooted practice as a social norm. Parental education is inversely associated with practicing FGC/M to their daughters. The socio-cultural reason was the main cause of practicing FGC/M among participants. Therefore, a significant change in factors such as education, and social development might cause a gradual decline in FGC/M.

\section{Background}

Female genital mutilation (FGM) comprises all procedures that involve partial or total removal of the external female genitalia, or other injury to the female genital organs for non-medical reasons. FGM is mostly carried out on young girls between infancy and age 15 and it is considered as violation of human rights of girls and women [1]. More than 200 million girls and women alive today have been cut in 30 countries in Africa, the Middle East and Asia where FGM is concentrated ${ }_{[2]}$.

World Health Organization (WHO) classified female genital mutilation into four different types. Type I, which is the mildest type, involves partial or total removal of the clitoris and/or the prepuce. Type II involves partial or total removal of the clitoris and the labia minora, with or without excision of the labia 
majora. Type III, also known as infibulation, involves the narrowing of the vaginal orifice through the creation of a covering seal by cutting and repositioning the labia minora and/or the labia majora, with or without excision of the clitoral prepuce/clitoral hood and glands. Type IV includes all other harmful procedures to the female genitalia for non-medical purposes, for example, pricking, piercing, incising, scraping, and cauterization of the genital area [1].

Documentation of the prevalence of different types of female genital mutilation began in the early twenties century with reports by European travelers and missionaries ${ }_{[3]}$. The Faculty of Medicine, University of Khartoum conducted the first national survey on female genital mutilation in Sudan in year 1979 [4]. Female genital cutting/mutilation (FGC/M) is deeply rooted and widely practiced in Sudan. The Multiple Indicator Cluster Survey (MICS) 2014 revealed that $86.6 \%$ of women aged 15-49 years were subjected to any form of FGC/M $[5]$. However, reduction in the prevalence of FGC/M is observed in most of states but at different levels. For example if we compared the FGC/M prevalence rate reported by the Safe Motherhood Survey $90.1 \%$ [6] with the recent prevalence, rate by the MICS. The reduction is slow and lagging behind what the situation demands. It is worth mentioning that the concerned bodies exerted intensified efforts to reduce FGC/M but the practice continues and expected to continue in the coming decades unless appropriate interventional strategies are implemented across the country. There are various factors that promote the continuation of $\mathrm{FGC/M}$ which include the following: religion, tradition, marriageability, sexual morals, health benefits, male preference, and social pressure ${ }_{[7]}$.

The harmful traditional practices were integrated into Sustainable Development Goals (SDGs), specifically Target 5.3 which called for eradication of FGM by year 2030 [8]. The eradication of FGC/M has been included within the national $\mathrm{RH}$ and other sectoral policies and strategies and the concerned bodies implemented interventional programs across the country but still the reduction in the prevalence is slow and lagging behind. It is of importance to identify the determinants of FGC/M at the state level to avail updated information for formulation/re-formulation of the current interventional strategies. This study was conducted to identify the determinants of FGC/M in Khartoum State, Sudan.

\section{Methods}

\section{Study design, area and population:}

A community based cross -sectional study was conducted in the Khartoum State, which is one of the 18 states of Sudan. It has an area of 22,122 km2. Khartoum, the national capital of Sudan is the capital of the Khartoum State. The study was conducted in three localities namely: Sharg Alneel, Umbadda and Bahri. For the purpose of the study, the study population included women in the reproductive age (15-49 years). According to 2008 population census, projection 2018, the population of Khartoum State is estimated to be 7, 993, 852 million people ${ }_{[9]}$ who are a mixture of tribes and ethnic groups of Sudan. The total census of women in reproductive age (15-49) in Khartoum State, projection 2018 [9] mounted to2, 
$014,382(25.2 \%)$. The demographic structure was almost similar to the parent population of the state and composed of different Sudanese tribes and ethnic groups.

\section{Sample size \& sampling technique:}

The sample size for the women in reproductive age (15-49 years) has been estimated using the following formula:

$$
\mathrm{n}=\frac{N}{1+N(e)^{2}}
$$

Where:

n: sample size

$\mathrm{N}$ : Total population $=\mathbf{2 , 0 1 4 , 3 8 2}$

e: degree of precision $=0.05$

Thus the estimated sample size $(n)=399.9$

Since the sampling technique planned to be used was multi-stage sampling technique rather than simple random technique; then it is necessary to multiply the estimated sample size by the design effect, which is approximately equal to 2 in order to improve representation.

Thus the sample size $=399.9 \times 2=799.8 \approx 800$. On the assumption that the non-response rate is $15 \%$, then the final estimated sample size $\underline{\underline{920}}$. The sample size was collected proportionate to size using multistage cluster sampling and participants were drawn using systematic probability sampling technique. The sample size was distributed proportional to the three selected localities as follows: Khartoum North Locality: 222, Sharq an-Nil Locality: 331 and Umbadda Locality: $\mathbf{3 6 7}$

\section{Data collection:}

A standardized administered questionnaire was developed, pre-tested, and used for quantitative data collection from interviewed women. The data collection team was composed of 3 field supervisors and 15 female data collectors. The data collectors were interested and motivated to work with full respect of dignity of the study participants and confidentiality required during data collection process. The data collectors and the field supervisors were trained for 2 days ( 12 working hours) on the following topics: objectives and justification of the study, contents of the questionnaire, communication skills, mock interview, filling of the questionnaire, sampling technique, editing and cleaning of the collected data, informed consent and ethical issues and field activities. Study variable were the following: Personal \& family characteristics i.e. educational level, age, age at marriage, type of FGC/M to which women were ever subjected, age of women when subjected to FGC/M, the percentage of interviewed women who 
approve FGC/M for their daughters, the reasons of interviewed women to approve FGC/M for their daughters and the socio-cultural reasons for continuity of FGC/M

\section{Data management and analysis:}

Completed questionnaires were checked and signed by the field supervisors for completeness, correctness and consistency of answers at the level of data collections sites. Statistical package for social sciences (SPSS) version 21 was used for analyzing the quantitative data set and generating outputs. Analysis was mostly univariate descriptive in order to generate indicators of interest. In addition, bi-variate analysis was conducted to find associations between variables of interest. Since most of the variables were categorical, associations between variables were determined using non-parametric tests such as Chi Square \& Fischer Exact tests. Analysis outputs were displayed as tabular and graphic formats. Multi-variate analysis was conducted to find associations between more than two variables using multinomial regression and Wald test. The study was estimated at $95 \%$ confidence level.

\section{Results}

\section{Table (1): Personal characteristic of the study participants}




\begin{tabular}{|lll|}
\hline Characteristics & Frequency & Percentage \\
\hline Age in years & & \\
\hline$<20$ & 15 & 1.6 \\
\hline 20-24 years & 60 & 6.5 \\
\hline 25-29 years & 125 & 13.6 \\
\hline 30-34 years & 164 & 17.8 \\
\hline 35-39 years & 190 & 20.7 \\
\hline 40-44 years & 150 & 16.3 \\
\hline$>$ 44 years & 216 & 23.5 \\
\hline Total & 920 & 100.0 \\
\hline Marital status & & \\
\hline Married & 817 & 88.8 \\
\hline Divorced & 37 & 4.0 \\
\hline Widowed & 60 & 6.5 \\
\hline Separated & 6 & 0.7 \\
\hline Total & 920 & 100.0 \\
\hline Age of marriage at first time & \\
\hline <20 & 438 & 47.6 \\
\hline 20- 24 years & 259 & 28.2 \\
\hline 25-29 years & 161 & 17.5 \\
\hline 30-34 years & 50 & 5.4 \\
\hline 35-39 years & 9 & 1.0 \\
\hline 40-44 years & 2 & 0.2 \\
\hline$>$ 44 years & 1 & 9.0 \\
\hline Total & 920 & \\
\hline Religion & & \\
\hline Moslem & 918 & \\
\hline Christian & 2 & \\
\hline Total & & \\
\hline
\end{tabular}




\begin{tabular}{|lll|} 
Current residence & \\
Urban & 713 & 77.5 \\
Rural & 20 & 2.2 \\
\hline Peri-urban & 187 & 20.3 \\
Total & 920 & 100.0 \\
\hline
\end{tabular}

Table (2): The age of practice of female genital cutting by the participants' families

\begin{tabular}{|lll|}
\hline Age of female genital cutting practice by participants' families & Frequency & Percentage \\
\hline Less than 4 years & 43 & 5.3 \\
\hline 4-5 & 155 & 19.1 \\
\hline $6-7$ & 386 & 47.5 \\
\hline $8-9$ & 160 & 19.7 \\
\hline $10-13$ & 64 & 7.9 \\
\hline More than 13 years & 4 & .5 \\
\hline Total & 812 & 100.0 \\
\hline
\end{tabular}

Table (3): Participant's educational level versus participant' daughters ever subjected to any form of female genital cutting 


\begin{tabular}{|c|c|c|c|c|c|}
\hline & & & \multicolumn{2}{|c|}{$\begin{array}{l}\text { Daughters have been subjected to any } \\
\text { form of female genital cutting }\end{array}$} & \multirow[t]{2}{*}{ Total } \\
\hline & & & No & Yes & \\
\hline \multirow{10}{*}{$\begin{array}{l}\text { Participant's } \\
\text { educational level }\end{array}$} & \multirow[t]{2}{*}{ Illiterate } & Count & 25 & 62 & 87 \\
\hline & & $\%$ & $28.7 \%$ & $71.3 \%$ & $100.0 \%$ \\
\hline & \multirow[t]{2}{*}{ Khalwah } & Count & 9 & 13 & 22 \\
\hline & & $\%$ & $40.9 \%$ & $59.1 \%$ & $100.0 \%$ \\
\hline & \multirow[t]{2}{*}{ Basic } & Count & 63 & 144 & 207 \\
\hline & & $\%$ & $30.4 \%$ & $69.6 \%$ & $100.0 \%$ \\
\hline & \multirow[t]{2}{*}{ Secondary } & Count & 106 & 135 & 241 \\
\hline & & $\%$ & $44.0 \%$ & $56.0 \%$ & $100.0 \%$ \\
\hline & \multirow{2}{*}{$\begin{array}{l}\text { University \& } \\
\text { above }\end{array}$} & Count & 181 & 54 & 235 \\
\hline & & $\%$ & $77.0 \%$ & $23.0 \%$ & $100.0 \%$ \\
\hline \multirow[t]{2}{*}{ Total } & & Count & 384 & 408 & 792 \\
\hline & & $\%$ & $48.5 \%$ & $51.5 \%$ & $100.0 \%$ \\
\hline
\end{tabular}

$P$ value $=.00$

Table (4): Type of the female genital cutting of the participants versus the type of female genital cutting of their daughters 


\begin{tabular}{|c|c|c|c|c|c|c|c|}
\hline & & & \multicolumn{5}{|c|}{$\begin{array}{l}\text { Type of female genital cutting ofparticipants' } \\
\text { daughters }\end{array}$} \\
\hline & & & Pharonic & Clitorectomy & $\begin{array}{l}\text { I do } \\
\text { not } \\
\text { know }\end{array}$ & Others & Total \\
\hline \multirow{8}{*}{$\begin{array}{l}\text { The type of female } \\
\text { genital cutting of } \\
\text { the participant }\end{array}$} & Pharonic & Count & 86 & 192 & 2 & 11 & 291 \\
\hline & & $\%$ & $29.6 \%$ & $66.0 \%$ & $0.7 \%$ & $3.7 \%$ & $100 \%$ \\
\hline & Clitorectomy & Count & 8 & 103 & 1 & 0 & 112 \\
\hline & & $\%$ & $7.1 \%$ & $92.0 \%$ & $0.9 \%$ & $0.0 \%$ & $100 \%$ \\
\hline & I do not & Count & 0 & 3 & 0 & 0 & 3 \\
\hline & & $\%$ & $0.0 \%$ & $100 \%$ & $0.0 \%$ & $0.0 \%$ & $100 \%$ \\
\hline & Others & Count & 1 & 0 & 0 & 0 & 1 \\
\hline & & $\%$ & $100.0 \%$ & $0.0 \%$ & $0.0 \%$ & $0.0 \%$ & $100 \%$ \\
\hline Total & & & 95 & 298 & 3 & 11 & 407 \\
\hline$\%$ & & & $23.3 \%$ & $73.0 \%$ & $0.8 \%$ & $2.5 \%$ & $100 \%$ \\
\hline
\end{tabular}

$P$ value $=.00$

Table (5): Participants' opinion about the person influence the decision to subject their daughters to $\mathrm{FGC/M}$ at the family level 


\begin{tabular}{|lll|}
\hline $\begin{array}{l}\text { The person influence the decision to subject their daughters to female } \\
\text { genital cutting }\end{array}$ & Frequency & Percentage \\
\hline Me & 359 & 39 \\
\hline My husband & 116 & 12.6 \\
\hline Both me \& my husband & 10 & 1.1 \\
\hline My mother & 198 & 21.5 \\
\hline My father & 5 & 0.5 \\
\hline Husband's mother & 99 & 10.8 \\
\hline Husband's father & 13 & 1.4 \\
\hline I do not know & 11 & 1.2 \\
\hline Nobody & 90 & 9.8 \\
\hline Others & 19 & 2.1 \\
\hline Total & 920 & 100 \\
\hline
\end{tabular}

Table (6): Multinomial logistic regression estimates of female genital cutting by family, participants and participants' daughters

\begin{tabular}{|lllllll|}
\hline Variable & B & S.E. & Wald & Df & Sig. & Exp(B) \\
\hline $\begin{array}{l}\text { Participants ever subjected to any form of } \\
\text { female genital cutting }\end{array}$ & -4.366 & .636 & 47.125 & 1 & .000 & .013 \\
\hline $\begin{array}{l}\text { Participants' daughters ever subjected to any } \\
\text { form of female genital cutting }\end{array}$ & -2.573 & .445 & 33.425 & 1 & .000 & .076 \\
\hline Constant & 4.294 & .421 & 103.847 & 1 & .000 & 73.244 \\
\hline
\end{tabular}

$B=$ Beta level of statistical significance, S.E $=$ Standard Error, $d f=$ Degree of freedom

Table (7): The main reasons for conduct of female genital cutting as perceived by the participants 


\begin{tabular}{|lll|}
\hline The reasons for conduct of female genital cutting & Frequency & Percentage \\
\hline Preservation of virginity & 232 & 25.2 \\
\hline Better marriage prospects & 51 & 5.5 \\
\hline Cleanliness/hygiene & 102 & 11.1 \\
\hline Customs \& traditions & 415 & 45.1 \\
\hline Religious & 52 & 5.7 \\
\hline Approval demanded by men & 27 & 2.9 \\
\hline I do not know & 36 & 3.9 \\
\hline Other & 5 & 0.5 \\
\hline Total & 920 & 100.0 \\
\hline
\end{tabular}

\section{Discussion}

Despite the efforts and interventions to eradicate FGC/M in Sudan, it remains a major public health problem. This study was prepared to answer questions related to the determinants of $\mathrm{FGC/M}$ at the state level to avail updated information for formulation/re-formulation of the current interventional strategies. The study was conducted in three localities in Khartoum state. $39.8 \%$ of the study participants were aged above 40 years. About $89 \%$ of the study participants were married and $48 \%$ of them got married for the first time at age less than 20 years. $99.8 \%$ of the study participants were Moslems and $77.5 \%$ were currently urban residents. The study revealed that the commonest age for such practice was 6-7 years as stated by about $48 \%$ of them. This is indicative of deeply rooted belief of the participants' families about $\mathrm{FGC} / \mathrm{M}$. It is accepted that FGC/M acts as social norms in communities where it is widely practiced. Thus families and individuals tend to do so as they believe that their community or groups expect them to practice ${ }_{[10]}$.

The participants' educational level versus participants' daughters ever subjected to any form of female genital cutting yielded statistically significant association (Chi-square value $=119.67$, df $4, P$ value $=.0001$ ) with tendency of the participants who attained educational level of university \& above to less subject their daughters to any form of female genital cutting. High parental educational level is associated with a lower prevalence rate of FGC/M among daughters. These results emphasize the importance of parental education in combating the continuity of FGC/M. Similar results were reported from studies in Egypt and Nigeria [11, 12, 13].

The type of female genital cutting of the participants versus the type of female genital cutting of their daughters, yielded statistically significant association (Chi-square value $=33.56$, $\mathrm{df} 9, \mathrm{P}$ value $=.001$ ) with tendency of the participants' daughters to be subjected to clitorectomy rather than pharonic. However, that indicates FGC/M is still widely practiced with shifting towards the less traumatizing clitorectomy. 
Although, almost $30 \%$ of the mothers who were subjected to pharonic type inclined towards conduct the same type for their daughters according to their social beliefs. Such a finding indicates that FGC/M is a custom that runs in the family as a continuous practice from mothers to daughters.

The study revealed the family practice of $\mathrm{FGC} / \mathrm{M}$ is predictor of prevalence of FGC/M among the study participants and their daughters. The result indicates the role of the family to influence the conduct of $\mathrm{FGC/M}$ although the influence is less observed on the participants' daughters to be subjected to FGC/M (table 6).

Regarding the decision for $\mathrm{FGC} / \mathrm{M}, 39 \%$ of the participants stated that they themselves influence the decision to subject their daughters to female genital cutting while $32 \%$ of them stated that the grandmothers influence such decision. The result revealed that the influence of the decision to subject daughters to FGC/M is shouldered mainly by the mothers and grandmothers. The results are comparable with a recent study in Sudan where $38.8 \%$ of the respondents stated that mother's girls initiated the discussion on the need to conduct FGC/M and $37.6 \%$ of them identified the mother as the person involved in decision of FGC/M type ${ }_{[14]}$. Similar results were reported from Ethiopia where the decision to have FGC/M was made by respondents' mothers, followed by grandmothers although the percentages

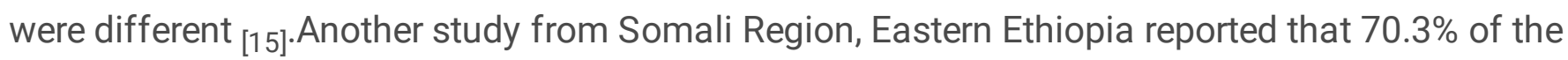
respondents stated that $\mathrm{FGC} / \mathrm{M}$ was decided by mother and $28.4 \%$ of them stated that both mother and father made the FGC/M decision and none of the participants mentioned that only father could decide by himself to conduct FGC/M for daughters ${ }_{[16]}$.

The study revealed that FGC/M is socio-cultural practice as $45 \%$ of the participants believed in customs and traditions as the main reason for conduct of FGC/M while $25 \%$ of them mentioned preservation of virginity and $6 \%$ mentioned religious reason (table 7). A study from Ghana documented the important reasons for conduct of FGC/M as traditions (44\%), control sexual desire (29\%) and social acceptance $20 \%$ [17]. Another study from Easter Ethiopia reported important reasons for continuity of FGC/M as preservation of virginity (61.8\%), religious reasons (18.1\%) and avoidance of sex-related problems $13.4 \%$ [16].

\section{Conclusions}

The results of the present study revealed that FGC/M is deeply rooted belief of the participants' families and thus most of the participants' families accepted it as social norms in communities where it is widely practiced. As revealed by the current study, a high parental educational level is associated with decrease practicing of FGC/M among daughters. These results emphasize the importance of parental education in combating the continuity of $\mathrm{FGC} / \mathrm{M}$. The participants had a tendency to subject their daughters to clitorectomy FGC/M type rather than pharonic. However, that indicates FGC/M is still widely practiced with shifting towards the less traumatizing clitorectomy. Such a finding indicates that FGC/M is a custom that runs in the family as a continuous practice from mothers to daughters. Moreover, the participants who were subjected to pharonic type inclined towards conduct of the same type for their daughters 
according to their social beliefs. However, the vast majority of the participants stated that they themselves and the grandmothers influenced the decision to subject their daughters to FGC/M indicating that the FGC/M of daughters is shouldered by the mothers and grandmothers. Social and cultural traditions were the main reason for conduct FGC/M. The social pressure associated with FGC/M was a key determinant of the persistence of the practice. Therefore, a significant change in factors such as education, and social development might cause a gradual decline in FGC/M. The available findings mainly suggest that it is necessary to adopt wide community-based interventions that address FGC/M holistically rather than health issue but as a violation of girls' and women's rights and gender-based violence. In addition, it is of importance to shift the interventional strategies at the community level towards behavioral communication change (BCC) with the involvement of families and individuals to abandon the FGC/M practice.

\section{List Of Abbreviations}

FGM: Female genital mutilation

FGC/M Female genital cutting /mutilation

MICS Multiple Indicator Cluster Survey

SDGs Sustainable Development Goals

SPSS Statistical Package for Social Sciences

IEC Information, education \& communication

df degree of freedom

SD Standard deviation

WHO World Health Organization

BCC Behavioral communication change

\section{Declarations}

\section{Ethics approval and consent to participate:}

An ethical approval was obtained from the Research Ethics Committee at Federal Ministry of Health. In addition, permissions were obtained from the authorities of the selected localities, administrative units and popular committees. An informed consent was obtained from each study participant prior to the interview. The collected data were kept confidential and accessed only by the research team members. If participants were children (under 16 years old), written informed consent for participation in the study was obtained from their parent or legal guardian before the interview was conducted. 


\section{Consent for publication:}

Not applicable.

\section{Availability of data and materials:}

The data are available from the corresponding author on reasonable request.

\section{Competing interests:}

The authors declare that they have no competing interests.

\section{Funding:}

The study was funded by the Sudan Family Planning Association (SFPA). SFPA has fully funded the research project. The fund has covered the expenses of proposal writing, implementation of field activities, statistical analysis and report writing.

\section{Authors' contributions:}

MKE conceptualized the study. MKE and RM participated in designing the study. RM , DA and TM collected the data and carried out data analysis. RM and MKE drafted and finalized the manuscript. MKI, SS, DA, and TM extensively reviewed and edited the manuscript. All authors contributed to interpreting study results and writing the manuscript. All authors read and approved the final manuscript.

\section{Corresponding author}

Correspondence to Reem Mahmoud.

\section{Acknowledgements:}

This study was financed by Sudan Family Planning Association. We would like to thank the study participants for their time and enthusiasm.

\section{Authors' information (optional)}

${ }^{1}$ Mustafa Khidir Mustafa Elnimeiri,MB. Bch. MD,Professor of Preventive Medicine \& Epidemiology,AlNeelain University,Khartoum, Sudan. ${ }^{2}$ Reem Mahmoud Mohamed Abdelbasit, MBBS, MPH Candidate, Teaching Assistant - Community Medicine Department, Al-Neelain University, Faculty of Medicine.

${ }^{3}$ Mohanad Kamaleldin Mahmoud Ibrahim, MBBS, MPH, PhD,Assistant Professor of Community Medicine, Ibn Sina University, Faculty of Medicine - Department of Community Medicine. ${ }^{4}$ Dimetry Adel Dimetry Mingaryous,MBBS, MPH candidate,Lecturer - Department of Community Medicine,Sudan International University, Faculty of Medicine. ${ }^{5}$ Taqwa Mohieldeen Hamid Abdelrahim, BSc, MSc Statistics, Statistician 
at Central Bureau of Statistics. ${ }^{6}$ Shahenaz Seifaldeen Mustafa Satti ,MBBS, Msc Clinical Physiology,Lecturer of Physiology,Faculty of Medicine, Al-Neelain University.

\section{References}

1. World Health Organization. Available at: https://www.who.int/news-room/fact-sheets/detail/femalegenital-mutilation. Accessed on 23.6.2020

2. Female Genital Mutilation/Cutting: a statistical overview and exploration of the dynamics of change, 2013.

3. World Health Organization. Female Genital Mutilation; an Overview. World Health Organization, Geneva 1998.

4. El Dareer A. Women, why do you weep? London Zed Press, 1982.

5. Sudan Ministry of Cabinet. Central Bureau of Statistics. Multiple Indicator Cluster survey (MICS), 2014

6. Federal Ministry of Health \& Central Bureau of Statistics, UNFPA. Safe Motherhood Survey, National report 1999.

7. Berg RC, Denison E. A tradition in transition: factors perpetuating and hindering the continuance of female genital mutilation/cutting (FGM/C) summarized in a systematic review. Health care for women international. 2013 Oct 1; 34(10):837-95.

8. World Health Organization. From MDGs to SDGs: general Introduction. Available at: https://www.who.int/gho/publications/mdgs-sdgs/MDGs-SDGs2015_chapter1.pdf. Accessed on: 22.2.2019

9. Sudan Central Bureau of Statistics: Projected Population, Khartoum State: available at:http://www.cbs.gov.sd. Accessed on 1.5.2019

10. United Nations Children's Fund, Female Genital Mutilation/Cutting: A statistical overview and exploration of the dynamics of change, UNICEF, New York, 2013.

11. Tag-Eldin MA, Gadallah MA, Al-Tayeb MN, Abdel-Aty M, Mansour E, Sallem M. Prevalence of female genital cutting among Egyptian girls. Bull World Health Organ. 2008; 86(4):269-274. doi:10.2471/blt.07.042093.

12. El-Zanaty F, Wavy AA. 13. Egypt interim demographic and health survey. Ministry of Health and Population, National Population Council, El-Zanaty and Associates, ORC Macro; 2004.

13. Ehigiegba A, Selo-Ojeme D \& Omorogbe F. Female circumcision and determinants in southern Nigeria. East African medical Journal 75, 374 $\pm 376,1998$.

14. Gamal Eldin, A, Babiker, S, Sabahelzain, M, Eltayeb, M. 2018. "FGM/C Decision-Making Process and the Role of Gender Power Relations in Sudan." Evidence to End FGM/C: Research to Help Girls and Women Thrive. New York: Population Council. 
15. Gebremariam K Assefa D, Weldegeb F. Prevalence and associated factors of female genital cutting among young adult females in Jigjiga district, eastern Ethiopia: a cross-sectional mixed study: International Journal of Women's Health 2016:8 357-365.

16. Abdisa B, Desalegn M, Tesew A (2017) Assessment of the Prevalence of FGM and Associated Factors among Women's of Reproductive Age Group in Kebirbeyah Town, Somali Region Eastern Ethiopia, 2017. Health Sci J. Vol. 11 No. 4: 517.

17. Berg RC, Denison E, Fretheim A. Factors promoting and hindering the practice of female genital mutilation/cutting (FGM/C). Report from Kunnskapssenteret nr 00-2010. Oslo: Norwegian Knowledge Centre for the Health Services, 2010.

\section{Supplementary Files}

This is a list of supplementary files associated with this preprint. Click to download.

- Questionnaire.docx

- STROBEchecklistcrosssectional.doc 